\title{
$O$ continente africano na política externa brasileira: de Jânio Quadros a Lula da Silva
}

\section{Kimberly Alves Digolin \\ Jonathan de Araujo de Assis \\ Débora Agata}

\begin{abstract}
“[A África] não é um continente estagnado, e representa um elemento fundamental para a inserção global do Brasil"'I
\end{abstract}

Resumo: O presente artigo busca realizar um levantamento histórico sobre o papel da África na diplomacia brasileira desde a implementação da Política Externa Independente - tendo em vista que para muitos autores esse é o marco inicial do africanismo na política externa brasileira -, perpassando o regime militar, o período de redemocratização e o governo de Fernando Henrique Cardoso, até os mandatos de Luiz Inácio Lula da Silva. A proposta do artigo também abriga um balanço mais detalhado sobre as relações com a África no período Lula da Silva, levando em conta a priorização dos países do Sul global e a posição privilegiada do continente vizinho na estratégia de inserção internacional adotada pelo presidente brasileiro.

Palavras-chave: Política Externa, Brasil, África.

\section{The African continent in Brazilian foreign policy: from Jânio Quadros to Lula da Silva}

Abstract: This article aims to conduct a historical survey on the role that Africa has played in Brazilian diplomacy since the implementation of "Política Externa Independente" - considering that for many authors this is the starting point of Africanism in Brazilian foreign policy -, also including the military regime, the democratization period, the government of Fernando Henrique Cardoso, and the mandates of Luiz Inácio Lula da Silva. This article also includes a more detailed assessment of relations with Africa in Lula da Silva's government, taking into account the prioritization of global South countries and the privileged position of the neighboring continent in the international strategy adopted by the Brazilian president.

Keywords: Foreign policy, Brazil, Africa.

Artigo recebido em 01/04/2016 e aprovado em 07/04/16. 


\section{KIMBERLY ALVES DIGOLIN, JONATHAN DE ARAUJO DE ASSIS E DÉBORA AGATA}

\section{Introdução}

Brasil e África estão intimamente ligados desde as colonizações portuguesas do século XVI. Os primeiros escravos africanos chegaram ao Brasil no final dos anos 1530, iniciando uma era de relações baseadas no tráfico que se estendeu por mais de três séculos. Nesse sentido, o continente africano pode ser compreendido enquanto "elemento essencial na formação econômica e na construção da identidade nacional"II .

No entanto, após sua independência, o Brasil sofreu grandes pressões por parte da Inglaterra, que demandava o término do comércio de escravos com a África. Com o fim do tráfico negreiro e o começo da expansão colonial europeia no continente africano, as relações entre ambos foram amplamente afetadas e assim permaneceram durante o século seguinte. Sob o contexto de Guerra Fria, a política externa brasileira se limitava aos contornos regionais, ficando em boa parte restrita às Américas. Exemplo disso é a falta de atenção ofertada pelo país às independências africanas durante o governo de Juscelino Kubitschek.

Foi apenas com o advento da intitulada "Política Externa Independente" (PEI), adotada ao longo do governo de Jânio Quadros e João Goulart, que a África retomou seu caráter de relevância na agenda brasileira. De acordo com Vizentini, "os laços históricos, a condição de país com grande população de afrodescendentes e o debate interno em torno da igualdade racial, estão presentes na visão brasileira sobre a necessidade de aproximação e cooperação" III, embora o autor ressalte a maior importância dos aspectos estratégicos e econômicos.

A partir disso, o presente artigo busca realizar um levantamento histórico sobre o papel da África na diplomacia brasileira desde a implementação da Política Externa Independente - tendo em vista que para muitos autores esse é o marco inicial do africanismo na política externa brasileira -, perpassando o regime militar, o período de redemocratização e o governo de Fernando Henrique Cardoso, até os mandatos de Luiz Inácio Lula da Silva. A proposta do artigo também abriga um balanço mais detalhado sobre as relações com a África no período Lula da Silva, levando em conta a priorização dos países do Sul global e a posição privilegiada do continente vizinho na estratégia de inserção internacional adotada pelo presidente brasileiro.

\section{Política Externa Independente}

Imersa em um contexto de redefinição da ordem mundial e, principalmente, de novas percepções sobre o papel do Brasil no sistema global, a PEI buscava "aumentar a participação brasileira nas questões internacionais e diversificar as relações com outros Estados, a fim de alcançar desenvolvimento econômico e projeção política condizente com as potencialidades do país" IV. Baseada nos princípios da universalização, autonomia, inserção internacional, não intervenção e autodeterminação dos povos, a PEI representou o início de uma nova posição brasileira frente à África, como mostra a mensagem do presidente Jânio Quadros ao Congresso Nacional, em 1961:

Não menos importantes, hoje em dia, do que os laços tradicionais que nos ligam à Europa, são os interesses, aspirações e pontos de contato entre o Brasil e os povos da 
África [...].Uma África próspera, estável, é condição essencial para a segurança e desenvolvimento do Brasil $^{\mathrm{V}}$.

Exemplo dessa nova priorização da África é a criação de um departamento específico no Ministério das Relações Exteriores do Brasil para abordar as questões e atividades relativas ao continente africano. É possível destacar também o apoio do presidente Quadros à independência argelina e o envio de um Grupo de Trabalho do Itamaraty para avaliar a possibilidade de novas representações diplomáticas brasileiras nos recém-independentes Estados africanos, cabendo ressaltar que vinte e sete países do continente vizinho haviam declarado independência entre 1950 e 1962. Foi a partir dos estudos desse grupo que foram criadas cinco novas embaixadas - em Costa do Marfim, Etiópia, Gana, Nigéria e Senegal -, além de novos consulados em Angola, Congo, Moçambique, Quênia e Rodésia do Sul.

No âmbito da Organização das Nações Unidas (ONU), o Brasil também apoiou a "Declaração sobre a Concessão da Independência aos Povos e Países Coloniais", através da qual quinze países da África puderam associar-se às Nações Unidas. Ademais, o governo de João Goulart inaugurou linhas marítimas especiais que ligavam o Brasil ao continente africano, buscando facilitar o intercâmbio comercial. Nesse sentido, o adensamento das relações com a África ampliava o perfil internacional do Brasil, fato que ajudava a "contrabalançar a exiguidade de meios financeiros e tecnológicos internos para a ação brasileira naquela porção quando comparada com o poder das antigas metrópoles" vI.

\section{Regime Militar}

No entanto, segundo Vizentini (2012), a partir de 1964 rompeu-se com esse primeiro esboço cooperativo, retomando não apenas o interesse em aumentar o mar territorial brasileiro para 200 milhas náuticas, mas também o enfoque geopolítico anticomunista e a questão da segurança coletiva - que implicou em uma reaproximação e cooperação com o regime racista da África do Sul e colonialista de Portugal. Os governos militares subsequentes ao golpe seguiram esse novo ordenamento da política externa brasileira e retrocederam as relações com a África, ainda que novas representações diplomáticas no continente tenham sido estabelecidas durante os mandatos de Castelo Branco e Costa e Silva, como as de Uganda, Tanzânia e Zâmbia.

Embora mantivesse pilares comuns aos demais governos militares, a política do governo Médici esboçou aproximação com a África em decorrência de interesses econômicos e estratégicos, como era o caso do aumento da demanda por mercados e matérias-primas em decorrência do "milagre econômico" no Brasil. Nesse sentido, é possível destacar o alto número de visitas ministeriais ao continente (dez delas apenas no biênio 1972-1973), tendo como destinos: Camarões, Costa do Marfim, Daomé, Gabão, Gana, Nigéria, Quênia, Senegal, Togo e Zaire. Entretanto, ainda que o governo Médici tenha abrigado tentativas de reaproximação com a África, foi apenas com o governo do General Ernesto Geisel que a África voltou a ocupar uma posição mais proeminente na política externa brasileira.

Geisel assumiu o comando do poder executivo entre 1974 e 1979 e assinalou o início de uma abertura política em meio ao regime militar. A política externa desse período ficou conhecida como "Pragmatismo Responsável e Ecumênico" e, em síntese, 
tratava-se de uma postura não-alinhada que visava o desenvolvimento nacional. Em outras palavras, a política desse período exprimia a "inexistência de aliados preferenciais, sem a definição a priori por um ou outro lado, e a busca por novos polos de interação" VII.

O governo Geisel foi marcado por um contexto internacional conturbado. Além do desaquecimento econômico mundial, por conta da Crise do Petróleo, o período também presenciou a deterioração do dólar em decorrência da Guerra do Vietnã e uma forte crise econômico-financeira na Europa. Ademais, é importante ressaltar os conflitos bélicos que tomavam espaço nas nações periféricas, inflados pela busca das superpotências em aumentar seus raios de ação e influência, principalmente na África Subsaariana, Oriente Médio e Sudeste Asiático.

Em meio a este contexto, as relações brasileiras com a África foram intensificadas, como mostra o discurso do presidente Geisel ao Congresso Nacional, em 1979:

[...] declarei, desde os primeiros dias, que meu Governo deveria praticar uma diplomacia pragmática, responsável e ecumênica. Fixei, nesse contexto, prioridade especial para as relações com nossos vizinhos d'aquém e d'além mar, da América Latina e da África, ao mesmo tempo que adotei a diretriz de evitarmos alinhamentos automáticos, fazendo correções de curso quando se tornassem necessárias VIII.

Esse novo, ou retomado, olhar ao continente africano pode ser exemplificado pelo aumento das visitas oficiais, missões diplomáticas, acordos bilaterais $\mathrm{e}$ multilaterais, além da participação em diversas reuniões internacionais. Entre elas: a Conferência Mundial sobre o Apartheid, em 1978; a Conferência Mundial de Combate ao Racismo e à Discriminação Racial, em 1978; a Conferência Mundial de Apoio aos Povos do Zimbábue e Namíbia; e a IV Reunião Anual da Junta de Governadores do Fundo Africano de Desenvolvimento.

Ademais, a Delegação do Brasil na ONU apoiou diversas resoluções e recomendações sobre a descolonização de países africanos, especialmente quanto aos territórios da Namíbia, Rodésia e Zimbábue. Também é importante citar o fortalecimento de relações da diplomacia brasileira com a África subsaariana, especialmente nas áreas de agricultura, educação e saúde, destacando-se as relações com a Nigéria - país que se tornou um dos principais parceiros comerciais do Brasil, exportando petróleo e importando alimentos, roupas e carros.

Durante o governo Geisel também foram criadas quatorze novas embaixadas em: Alto Volta; Angola; Cabo Verde; Gabão; Guiné; Guiné Equatorial; Maurício; Moçambique; Reino de Lesoto; Reino da Suazilândia; República da Libéria; República Popular do Congo; São Tomé e Príncipe; e Serra Leoa. É importante destacar que a diplomacia do "Pragmatismo Responsável" também foi fortemente marcada por um discurso terceiro-mundista e pela condenação dos regimes racistas da África do Sul e Rodésia, tendo sido o primeiro país a reconhecer o governo de viés marxista do Movimento Popular de Libertação de Angola (MPLA), em 1975, e o primeiro a reconhecer a independência de Guiné-Bissau, em 1974.

Ainda no regime militar, o presidente Ernesto Geisel indicou para sua sucessão o candidato João Baptista Figueiredo, eleito em 1978. O General Figueiredo defendia o 
processo de redemocratização, contextualizado em um cenário adverso onde $o$ capitalismo já não proporcionava a concepção de projeto desenvolvimentista para um país com tamanhas medidas, enfrentando ainda a crescente manifestação oposicionista e a intensa mobilização social interna. Figueiredo também vivenciou o segundo choque do petróleo e a revolução científico-tecnológica, que acentuou o abismo existente entre países desenvolvidos e em desenvolvimento. A somatória de todos esses acontecimentos, internos e externos, acabou por comprometer o projeto nacional e certas conquistas econômicas.

Concernente à atuação externa, apesar de ter mantido relações com a África, os laços entre Brasil e África Austral foram enfraquecidos pela recessão econômica e intensificação da guerra no extremo do continente vizinho. Ainda assim, o Itamaraty manteve sua posição contrária ao apartheid e em favor da não militarização do Atlântico Sul, além de efetivar sua relação de troca de petróleo por bens e serviços em prol da cooperação econômica com Angola. O Brasil também estabeleceu relações diplomáticas com Belize, Birmânia, Dominica, Iêmen, Ruanda e Zimbábue, consolidando seus vínculos no âmbito econômico, político e cultural. Figueiredo também foi o primeiro presidente brasileiro a visitar oficialmente a África, viajando para a Argélia, Cabo Verde, Guiné Bissau, Nigéria e Senegal.

De modo geral, durante esse período, o Brasil reforçou sua postura de cooperação Sul-Sul baseada na horizontalidade e na não-imposição de hegemonia. Foi com o apoio dessa política externa mais universalista que Figueiredo conseguiu aprofundar os planos iniciados por Geisel. No entanto, segundo Gonçalves e Miyamoto (2014), não foi a ideologia, mas sim os interesses econômicos e estratégicos que caracterizaram a política africana do período, como demonstra a ameaça de intervenção brasileira em favor de Angola na região.

Em síntese, os dois últimos mandatos presidenciais do regime militar brasileiro deixaram um saldo positivo no que diz respeito à política externa brasileira com a África, exemplificado pelo aumento do número de embaixadas brasileiras no continente, que passou de 12 em 1974, para 21 em 1984. Além disso, a reestruturação ocorrida no Itamaraty com a subdivisão do Departamento da África também denota maior priorização e especificidade às relações com o continente vizinho, sendo essa também a tendência percebida nos anos seguintes.

\section{Redemocratização}

O processo de redemocratização política no Brasil teve início em 1985 quando José Sarney assumiu a presidência da denominada Nova República, após vinte e um anos de regime militar. No entanto, vale ressaltar que o novo modelo político era formado por uma coalizão liderada pelo Partido da Frente Liberal (PFL) e pelo Partido do Movimento Democrático Brasileiro (PMDB), financiados por militares que ainda controlavam a transição do país e estabeleciam limites de maneira paralela.

Esses resquícios de interferência militar, porém, não tiveram muito impacto sobre a política externa brasileira que Sarney buscava seguir. Durante discurso proferido ao Congresso, em 1986, o presidente expôs seu interesse em criar uma nova ordem econômica internacional, com ênfase na solução das dívidas externas do Terceiro Mundo, priorização da América Latina, destaque à situação do Oriente Médio, incremento das relações com a África e repúdio ao apartheid sul-africano, além de 
maior cooperação com os países de economia planejada e fortalecimento da ONU e outras organizações internacionais.

A existência de um novo paradigma na integração latino-americana tornou as relações com os Estados Unidos instáveis, fazendo com que Washington instituísse sanções comerciais e retaliações à iniciativa brasileira, além de recomendar que os países da América Latina adotassem políticas econômicas de disciplina fiscal, incluindo liberalizações comerciais, privatizações e desregulamentações.

Em decorrência dessas retaliações, a diplomacia brasileira lançou novo foco para a cooperação Sul-Sul, na tentativa de demonstrar maior independência frente ao governo norte-americano. O presidente Sarney ainda propôs a Declaração de Zona de Paz e Cooperação do Atlântico Sul (Zopacas), aprovada pela ONU em 1986, que visava maior cooperação regional e manutenção da paz entre países da região, buscando diminuir ao máximo a proliferação de armas nucleares e a presença de militares externos à organização.

No entanto, imersa em cenários doméstico e internacional abalados pela crescente crise financeira e fim da Guerra Fria, respectivamente, a política externa do presidente Fernando Collor destoou consideravelmente da diplomacia multilateral empregada no governo Sarney. A partir da posse de Collor, em 1990, houve uma reaproximação com os Estados Unidos, retomando foco no continente americano e implementando um processo de liberalização da economia.

A alta inflação brasileira motivou Collor a estabelecer medidas econômicas de contenção. Entretanto, essas ações não alcançaram os resultados esperados e geraram desconfiança na comunidade financeira internacional, mesmo com a eliminação de diversas taxas de comércio internacional que deixaram de salvaguardar os produtos brasileiros. Buscando aumentar sua base de apoio, Collor nomeou Celso Lafer como novo ministro das Relações Exteriores em 1992.

Ao assumir, Lafer priorizou o êxito da Conferência Rio-92, bem como a defesa da liberdade, democracia, respeito aos direitos humanos e desenvolvimento sustentável. Concomitantemente, o Brasil ainda pleiteava um assento permanente no Conselho de Segurança das Nações Unidas, ressaltando sua contribuição com as forças de paz da organização, embora acreditasse que seu ingresso ocorreria através da renúncia dos recursos de poder e não pela conquista de uma posição sólida em âmbito externo. Com isso, o Brasil afastou-se cada vez mais da África, Ásia, Oriente Médio e outras regiões periféricas do sistema internacional.

Após a conclusão de um processo de impeachment, Collor foi afastado do Poder Executivo, assumindo o então vice-presidente Itamar Franco, em outubro de 1992. Itamar nomeou Fernando Henrique Cardoso (FHC) para a administração do Ministério das Relações Exteriores, o qual afirmava que o objeto da política externa brasileira deveria ser a integração democrática do país no sistema internacional. Nesse sentido, o governo do período tinha a incumbência de revalorizar o Brasil no cenário internacional através da participação em foros multilaterais e na integração regional.

Ao assumir a pasta da Fazenda, FHC foi substituído pelo diplomata Celso Amorim, que propôs uma agenda de desenvolvimento ligada à manutenção da paz - a qual resolveu pendências econômico-comerciais com diversos países e desenvolveu parcerias através do Mercado Comum do Sul (Mercosul) e da Comunidade dos Países de Língua Portuguesa (CPLP). Além disso, Amorim também destacou a importância da Zopacas, corroborando com a defesa de um sistema multilateral de comércio e 
integração regional, ao mesmo tempo em que buscava combater o protecionismo dos países mais centrais e promover acesso às novas tecnologias.

\section{Fernando Henrique Cardoso}

Para compreender de maneira mais completa o governo de FHC e as relações brasileiras com a África, é importante pontuar o contexto no qual o Brasil estava inserido à época. Internamente, os benefícios do Plano Real já começavam a ser observados e o seguimento da Cartilha Neoliberal de Washington tomava corpo com a simplificação da máquina estatal e intensificação do programa de privatizações estabelecido pelo governo.

Já no âmbito internacional, a Nova Ordem Mundial exprimia forte necessidade de renovação na forma como o Brasil dialogava com os demais países. Ou seja, com a expansão de poder dos Estados Unidos, o Brasil optou por uma inserção que fortalecia o eixo Norte-Sul, baseado na concepção de que "a busca da credibilidade frente aos países centrais teria como contrapartida reconhecimento político, concessões comerciais e ajuda financeira e tecnológica" IX .

Tais fatos refletiram na política externa brasileira, que ganhou destaque e passou a enfatizar os processos de integração regional, as negociações multilaterais e a abertura comercial. Além disso, a prevalência de um ambiente internacional cooperativo baseado na democratização das instituições, em especial no âmbito comercial, favoreceu algumas das conquistas alcançadas pelo governo FHC na área diplomática.

Segundo Vigevani e Cepaluni (2007), o período catalisou a tendência de se buscar "autonomia pela participação", uma vez que tal medida poderia favorecer os interesses brasileiros e restaurar a imagem externa do país. Nesse sentido, a autonomia brasileira deixava de ser entendida como afastamento das questões internacionais e passava a compreender participação e influência na agenda global, sempre em congruência com os valores tradicionais da diplomacia brasileira. Ou seja,

se até 1988 os parâmetros da política externa, sob governos autoritários ou sob o governo civil a partir de 1985, davam sentido para políticas protecionistas, voltadas para a idéia da "autonomia pela distância", na nova configuração internacional haveria a necessidade de incorporar na agenda externa do país a defesa dos direitos humanos, a proteção ambiental, a transição democrática, os direitos sociais e, no campo econômico, as reformas liberais, a abertura e a aceleração da integração latinoamericana $\mathrm{X}$.

Em discurso realizado ao Congresso Nacional em 1995, FHC apontou os princípios que norteariam a política externa de seu governo, entre eles: defesa dos direitos humanos, do meio ambiente e das minorias; combate ao narcotráfico; e abertura econômica em prol de uma maior competitividade brasileira no âmbito externo. Ademais, o presidente apontou como objetivos dessa política externa a reforma estrutural da ONU e maior participação nacional nos processos decisórios regionais e globais, bem como nos fóruns políticos e econômicos. Fernando Henrique Cardoso também fez uso em larga escala da diplomacia presidencial através de visitas oficiais, participação em encontros bilaterais ou multilaterais e assinaturas de acordos e tratados. 
Concernente à África, houve uma clara redução do seu papel na política externa brasileira. Em 1990, o corpo diplomático brasileiro presente em missões no continente africano foi reduzido pela metade e deslocado para áreas de maior prioridade, incluindo Europa, Estados Unidos e América do Sul. Segundo Saraiva (2002), as relações com a África foram ajustadas a um "contexto atlântico", categorizadas como sendo de pouca relevância para a inserção internacional do país.

A África ficou fora do norte da política externa do Brasil nos anos 1990. O Brasil se deixou contaminar pela interpretação ingênua das relações internacionais kantianas, em torno das quais as saídas para a modernidade estavam no multilateralismo e no esforço da construção de uma agenda global consensual e na regulação de temas globais como o liberalismo econômico, o meio ambiente, os direitos humanos, entre outros. Essa confusão conceitual levou ao abandono de ricos caminhos anteriores já trilhados pelo Brasil na África, emanados pelo modelo de substituição de importações e da política de promoção de exportações ${ }^{\mathrm{XI}}$.

Além disso, é importante destacar que apesar do Ministro das Relações Exteriores do Brasil à época, Luiz Felipe Lampreia, sempre apontar em seus discursos a necessidade de se reconhecer a atuação da CPLP, bem como a importância de se mediar as crises internas de Angola, Guiné-Bissau e Timor Leste, houve uma fusão do Departamento da África (DEAF) e do Departamento do Oriente Próximo (DEOP) do Ministério das Relações Exteriores, o que sugere uma falta de prestígio de ambas as regiões na pauta externa brasileira.

Entretanto, o período abrigou "algumas iniciativas importantes e certa inflexão ao longo do segundo mandato, que viriam a ser qualitativamente aprofundadas pelo governo Lula" XII. A maior participação em missões de paz e a cooperação no campo das políticas públicas são exemplos disso. Ademais, a crítica à globalização assimétrica também gerou maior convergência na diplomacia internacional em fóruns multilaterais, especialmente os de caráter comercial. A visita de FHC à África do Sul em 1996, por exemplo, serviu de pontapé inicial para as negociações entre o país africano e o Mercosul, bem como para a criação de uma área de livre comércio estabelecida por ambos.

\section{Luiz Inácio Lula da Silva}

Após assumir o cargo de Presidente da República, em 2003, Luiz Inácio Lula da Silva apontou que o fundamento orientador das políticas públicas de seu governo seria a mudança. Pautas de natureza econômica e, sobretudo, social ganharam relevo em sua administração, visando o equilíbrio entre crescimento e desenvolvimento. Dessa forma, a política externa brasileira empreendeu esforços a fim de fortalecer a temática social no contexto internacional, além de promover maior cooperação com países sul-americanos, árabes e africanos.

As ações voltaram-se à manutenção da estabilidade macroeconômica herdada da gestão anterior, sobretudo para garantir a exequibilidade dos programas sociais pautados pelo novo programa de governo. Com o plano macroeconômico sob controle, foi 
possível qualificar o padrão de vida das camadas menos favorecidas da população, ao passo que as contas externas sofreram um significativo incremento das exportações e dos investimentos diretos estrangeiros, contribuindo para a saúde da balança de pagamentos do país XIII.

Com o plano interno estável, por consequência direta do encaminhamento da política econômica, o governo Lula da Silva atingiu altos índices de aprovação entre os brasileiros, fatos que credenciaram o Brasil a projetar-se internacionalmente. Dessa forma, e apesar do expressivo papel exercido pelo Ministério das Relações Exteriores (MRE) enquanto executor da política externa brasileira, houve também um fortalecimento da prática de diplomacia presidencial, a qual permitiu um estreitamento nas relações de cooperação com diversos países.

No que se refere ao ambiente externo, o MRE identificara os principais pontos que caracterizavam as realidades regionais e internacionais, podendo ser destacados: a tendência ao ambiente "uni-multipolar" no sistema internacional após os atentados de 2001; e a possibilidade dos Estados Unidos priorizarem temas vinculados a questões de segurança internacional em detrimento de assuntos voltados ao desenvolvimento e temas globais ${ }^{X I V}$. Nesse sentido, a política externa do governo Lula da Silva foi orientada pela concepção de que o Brasil deveria assumir um papel mais influente no cenário internacional, projetando uma imagem mais ativa e altiva, nas palavras do ministro Celso Amorim. A cooperação Sul-Sul foi um dos grandes pilares dessa política, com especial destaque para a América do Sul e o continente africano.

De acordo com Saraiva (2002), as relações brasileiras com a África passaram por períodos de "silêncio e afastamento" durante os anos 1990, cabendo ao presidente Lula da Silva retomar e revalorizar esse tópico. Nesse sentido, ainda que a relação com os países sul-americanos tenha apresentado certa continuidade com o período anterior tendo em vista que o maior estreitamento de laços com os países vizinhos tinha sido uma das estratégias do presidente FHC para aumentar seu espaço de manobra perante um crescente unilateralismo estadunidense -, a diplomacia brasileira de Lula da Silva foi inovadora no relacionamento com o continente africano.

Essa reorientação também foi catalisada pelo contexto favorável vivido no continente contíguo, expresso pelo fim das guerras civis nos países lusófonos, fim do apartheid na África do Sul e pela crescente integração dos países africanos, culminada na criação da União Africana (UA) em 2001. De acordo com Vizentini ${ }^{X V}$, as relações entre Brasil e África superaram a retórica e ganharam um novo impulso a partir do governo Lula da Silva. Em discurso realizado durante sessão solene de posse no Congresso Nacional, em 2003, o presidente ressaltou a existência de laços profundos entre Brasil e o continente africano, bem como a busca por "contribuir ativamente para que ele desenvolva as suas enormes potencialidades" XVI.

Como exemplo desse maior enfoque à África é possível citar o expressivo número de visitas oficiais entre autoridades brasileiras e africanas. Ao longo de seus dois mandatos, o presidente Lula da Silva realizou 33 viagens ao continente, visitando 23 países - inclusive países aos quais nenhum presidente brasileiro havia visitado. Já o ministro Celso Amorim esteve no continente 66 vezes, visitando 25 países diferentes. Além disso, entre 2003 e 2010, o Brasil recebeu 109 visitas oficiais de presidentes, reis, primeiros-ministros e chanceleres africanos.

O Brasil promoveu relações e parcerias principalmente nos âmbitos políticodiplomáticos, de investimentos diretos e cooperação técnica. Com isso, o país garantiu 
acesso a novos mercados e maior influência em foros multilaterais, como é o caso do G20 Comercial - criado em 2003, às margens da Cúpula Ministerial de Cancún da Organização Mundial do Comércio (OMC), e formado por 23 países emergentes com foco na agricultura. Atualmente, o fórum é um dos mais influentes no que se refere à negociação agrícola dentro da OMC, promovendo o debate entre países industrializados e emergentes e defendendo o acesso a mercados.

Inserido na pauta externa brasileira, o G-20 tornou-se um fórum de grande relevância para a diplomacia nacional, inclusive apontando o Brasil como um ator participativo e propositivo nas negociações dentro da OMC. Segundo Saraiva, o país "buscou uma atuação mais ativa de defesa da perspectiva brasileira nas negociações na OMC em ação conjunta com outros países em desenvolvimento, dando prioridade ao equilíbrio dos benefícios recebidos por países mais desenvolvidos e em desenvolvimento" XVII.

Como exemplos dessa nova forma de atuação e, em certo ponto, priorização das tratativas com países em desenvolvimento, é possível citar as declarações do presidente Lula da Silva após a Cúpula de Seul, em 2010, quando o mandatário defendeu a "diminuição dos desequilíbrios entre ricos e pobres através de mudanças nas entidades financeiras mundiais e declarou que há a necessidade de integração entre os países do Sul para que deixem de ser submissos aos do Norte" XVIII.

Um resultado palpável dessa linha política foi a escolha do diplomata brasileiro Roberto Azevêdo ao posto de diretor-geral da OMC, que, embora tenha se concretizado após o fim do mandato de Lula da Silva, decorre diretamente dessa intensa relação com os países em desenvolvimento, principalmente da África. Nesse caso, é importante ressaltar que também concorria ao cargo o mexicano Herminio Blanco, com apoio dos Estados Unidos e da União Europeia.

Também foi durante o governo Lula da Silva que ocorreu a criação do Fórum de Diálogo Índia, Brasil e África do Sul (IBAS), em 2003. O Fórum foi uma iniciativa sulafricana que almejava a construção de uma nova arquitetura internacional, baseada na concertação política e na cooperação setorial. De acordo com Saraiva, o IBAS constituiu-se um forte espaço político para a atuação brasileira no cenário internacional, além de alertar a comunidade internacional que "os países estão dispostos e aptos a quebrar o invólucro de seus contextos regionais e colaborar decisivamente para os progressos de uma ordem multipolar"XIX.

Outro importante exemplo dessa aproximação com os países periféricos foi a criação da Cúpula América do Sul-África (ASA) em 2006, a partir de uma proposta nigeriana e iniciativa da diplomacia brasileira. A Cúpula é composta pelos 12 países sul-americanos e 56 Estados africanos, com encontros bianuais ou trienais, além das reuniões dos Grupos de Trabalho. A ASA envolve temas diversos, que vão desde infraestrutura até questões sociais e esportes, revelando os esforços gerais do Brasil em:

aprofundar o ativismo internacional através de múltiplas iniciativas, tais como o incentivo à internacionalização de empresas; o fortalecimento de laços com os vizinhos sulamericanos; a atuação protagônica em esferas multilaterais, como a coalizão G20 na OMC; a formação de coordenações políticas com países emergentes (IBAS, BRICS); entre outros $\mathrm{XX}$. 
O Brasil também acentuou relações com a CPLP, a qual reúne oito Estados que adotam o português como língua oficial, sendo cinco deles situados na África - Angola, Cabo Verde, Guiné-Bissau, Moçambique e São Tomé e Príncipe. Esses países receberam quase metade dos recursos brasileiros destinados à cooperação técnica, especialmente em agricultura e combate ao vírus HIV.

Também vale destacar que o Brasil possui delegação permanente junto à Comunidade desde 2006 e a sua maior participação foi fundamental para que a CPLP atuasse na resolução de crises no Timor Leste e Guiné-Bissau, bem como no monitoramento de eleições em diversos países lusófonos. Além disso, segundo a Subsecretaria-Geral de Cooperação e de Promoção Comercial do Brasil, os países de língua portuguesa receberam $77 \%$ das ações de cooperação brasileira na África em 2007.

O tema de educação também foi alvo de grandes parcerias e projetos cooperativos, com destaque para a Universidade Federal da Integração Luso-AfroBrasileira (Unilab) - criada em 2010, com sede no Ceará-, que recebe estudantes e professores de países africanos de língua portuguesa com base na cooperação solidária. Além disso, desde 2003, o Instituto Rio Branco também possui acordos de cooperação com academias diplomáticas do Marrocos, Egito e Quênia.

Com relação à área de Inovação, o Programa de Cooperação Temática em Matéria de Ciência e Tecnologia (ProÁfrica) financiou 151 projetos entre 2005 e 2008, cabendo ressaltar ainda o acordo de criação de um satélite conjunto no âmbito do IBAS. Outro aspecto de grande relevância na área de cooperação entre Brasil e África é o esporte, por meio de acordos, treinamentos e projetos de inserção social. Durante os mandatos de Lula da Silva, o Brasil ainda firmou acordos de cooperação na área de Defesa com sete países, criando um Centro de Formação de Forças e Segurança, e uma Missão de Cooperação Técnico-Militar em Guiné-Bissau, além de apoiar o relançamento da Zopacas.

Essas iniciativas políticas com o continente africano também geraram retornos econômicos para o país. Segundo o balanço oficial do período, o intercâmbio entre Brasil e África passou de US\$5 bilhões em 2002, para US\$28 bilhões em 2008, tornando-se o quarto maior parceiro comercial brasileiro. A política de cooperação SulSul do período ainda gerou reflexos na estrutura organizacional do Itamaraty, como a nova separação do Departamento da África e Oriente Próximo (DAOP), fato que denota maior priorização e especificidade para as relações com países dessas regiões. Ademais, ao final do governo Lula da Silva, o Brasil possuía 34 embaixadas em países africanos, sendo que metade destas foram abertas ou reabertas entre 2002 e 2010.

Em síntese, durante o governo Lula da Silva houve certa contraposição à postura adotada pelo governo anterior - que fora marcado pelo contexto de guerras civis e retrocesso econômico em grande parte dos países da África, assim como por dificuldades nacionais. A diplomacia brasileira priorizou as relações Sul-Sul buscando aumentar seu protagonismo internacional, postura esta que Vigevani e Cepaluni (2007) conceituaram como "autonomia pela diversificação", sobretudo no que diz respeito ao continente africano, uma vez que "[o] situou no mais elevado patamar de prioridade em termos de investimento diplomáticos do governo, só superada pela América do Sul” XXI.

\section{Considerações Finais}


É possível notar que apesar de a África em nenhum momento ter sido abandonada pela política externa brasileira, houve períodos de maior proximidade com o continente, sendo eles: a Política Externa Independente dos governos Jânio Quadros e João Goulart (1961-1964); o Pragmatismo Ecumênico e Responsável de Geisel e sua continuidade durante o governo do General Figueiredo (1974-1985); e a política de cooperação sul-sul dos governos Lula da Silva (2003-2010). No caso do governo Lula da Silva, essa aproximação foi tão expressiva que denotou uma inflexão na política externa brasileira, uma vez que ao defender a soberania nacional e o multilateralismo, o país passou a atuar no cenário internacional de maneira mais proeminente e propositiva, sem abandonar seus modelos e valores tradicionais.

Segundo Pautasso e Albanus (2012), esse modelo baseou-se na ideia de que a participação em fóruns multilaterais poderia aliviar as insuficiências de poder do país, em benefício de uma maior projeção internacional brasileira. Além disso, a natureza dos esforços empreendidos em favor de uma maior aproximação com países do eixo "periférico", ao mesmo tempo em que promovia a manutenção das relações com os Estados desenvolvidos, conferiu à diplomacia brasileira maior legitimidade.

A posição adotada em relação ao continente africano pelo governo de Lula da Silva alinhava-se à postura geral da política externa brasileira durante o período, qual seja, aprimorar as relações internacionais do país através de um incremento de parceiros e buscar acordos de natureza diversificada. A fim de ilustrar essa questão, é possível destacar os acordos em matéria de Defesa assinados pelo Brasil, tanto com a França para a construção de um submarino nuclear, como com a África do Sul para o desenvolvimento conjunto de um míssil ar-ar de quinta geração. No caso do último país, o Brasil possui ainda uma ampla agenda de temáticas discutidas e negociadas no âmbito do IBAS.

Em suma, e frente às informações aqui cotejadas, atribui-se às próximas administrações do Executivo brasileiro a incumbência de proporcionar avanços sobre as iniciativas lançadas pelos últimos governos, bem como consolidar a ideia de uma política externa disposta a promover maior autonomia política para o país. Nesse sentido, o fortalecimento das relações com os países do continente africano pode apresentar-se enquanto plataforma política para a legitimação de um processo revisionista das estruturas de poder internacionais. Em outras palavras, pode atender às demandas dos países emergentes e em desenvolvimento através do estabelecimento de uma efetiva multipolaridade na multilateralidade.

\section{Notas}

\footnotetext{
' Vizentini, P. G. F. (2010). South-South cooperation, prestigie diplomacy or “soft imperialism"? Lula's government Brazil-Africa relations. Século XXI [online]. Disponível em: http://sumarioperiodicos.espm.br/index.php/seculo21/article/view/1706/31 [Acesso em 15 Setembro 2014].

"Pimentel, J. V. (2000). Relações entre o Brasil e a África subsaárica. Revista Brasileira de Política Internacional [online]. Disponível em: http://www.scielo.br/pdf/rbpi/v43n1/v43n1a01.pdf [Acesso em 15 Setembro 2014].

III Vizentini, P. G. F. (2010). South-South cooperation, prestigie diplomacy or "soft imperialism"? Lula's government Brazil-Africa relations. Século XXI [online]. Disponível em: http://sumarioperiodicos.espm.br/index.php/seculo21/article/view/1706/31 [Acesso em 15 Setembro 2014].
} 
IV Leite, P. S. (2011).O Brasil e a cooperação Sul-Sul em três momentos [livro eletrônico] Brasília: Fundação Alexandre de Gusmão. Disponível em: http://www.funag.gov.br/biblioteca/dmdocuments/Cooperacao_sul_sul.pdf[Acesso em 15 Setembro 2014].

$\checkmark$ Muniz, C. B. A. (2009). Discursos selecionados do Presidente Jânio Quadros. [livro eletrônico] Brasília: Fundação Alexandre de Gusmão. Disponível em: http://www.funag.gov.br/biblioteca/dmdocuments/Discursos_janio_quadros.pdf [Acesso em 15 Setembro 2014].

${ }^{V 1}$ Leite, P. S. (2011).O Brasil e a cooperação Sul-Sul em três momentos [livro eletrônico] Brasília: Fundação Alexandre de Gusmão. Disponível em: http://www.funag.gov.br/biblioteca/dmdocuments/Cooperacao_sul_sul.pdf[Acesso em 15 Setembro 2014].

VII Mendonça, F. A. P.; Miyamoto, S. (2011). A política externa do governo Geisel (1974-1979). Século XXI [online], 2.2 Disponível em: periodicos.espm.br/index.php/seculo21/article/viewFile/1822/100[Acesso em 15 Setembro 2014].

VIII Castro, F. M. O. (2009), Dois séculos de história da organização do Itamaraty. [livro eletrônico] Brasília: Fundação Alexandre do Gusmão. Disponível em: http://www.funag.gov.br/biblioteca/dmdocuments/Historia_da_org_do_itamaraty_vol_1.pdf [Acesso em 15 Setembro 2014].

${ }^{1 x}$ Pecequilo, C. S. A Política Externa do Brasil no século XXI: os eixos combinados de cooperação horizontal e vertical. Revista Brasileira de Política Internacional [online]. Disponível em: http://www.scielo.br/pdf/rbpi/v51n2/v51n2a09.pdf [Acesso em 15 Setembro 2014].

x Vigevani, Tullo; Cepaluni, G. (2007). A política externa de Lula da Silva: a estratégia da autonomia pela diversificação. Contexto Internacional [online], 29. Disponível em: http://www.scielo.br/pdf/cint/v29n2/v29n2a02.pdf[Acesso em 15 Setembro 2014].

${ }^{x \mid}$ Saraiva, J. F. S. (2002). Política exterior do governo Lula: o desafio africano. Revista Brasileira de Política Internacional [online], 45. Disponível em: http://www.scielo.br/pdf/rbpi/v45n2/a01v45n2.pdf [Acesso em 15 Setembro 2014].

XII Vizentini, P. G. F.; Pereira, A. D.A política Africana do governo Lula [online]. Disponível em: http://www.ufrgs.br/nerint/folder/artigos/artigo40.pdf [Acesso em 18 Setembro 2014].

XIII Castro, F. M. O. (2009), Dois séculos de história da organização do Itamaraty. [livro eletrônico] Brasília: Fundação Alexandre do Gusmão. Disponível em: http://www.funag.gov.br/biblioteca/dmdocuments/Historia_da_org_do_itamaraty_vol_1.pdf [Acesso em 15 Setembro 2014].

xiv Castro, F. M. O. (2009), Dois séculos de história da organização do Itamaraty. [livro eletrônico] Brasília: Fundação Alexandre do Gusmão. Disponível em: http://www.funag.gov.br/biblioteca/dmdocuments/Historia_da_org_do_itamaraty_vol_1.pdf [Acesso em 15 Setembro 2014].

xV Vizentini, P. G. F.; Pereira, A. D.A política Africana do governo Lula [online]. Disponível em: http://www.ufrgs.br/nerint/folder/artigos/artigo40.pdf [Acesso em 18 Setembro 2014].

xvI Brasil. (2008). Discursos selecionados do Presidente Luiz Inácio Lula da Silva. [livro eletrônico] Brasília: Fundação Alexandre de Gusmão. Disponível em: http://funag.gov.br/loja/download/505discursos_selecionados_lula.pdf [Acesso em 15 Setembro 2014].

xVII Saraiva, M. G. (2007). As estratégias de cooperação Sul-Sul nos marcos da política externa brasileira de 1993 a 2007. Revista Brasileira de Política Internacional [online], 50. Disponível em: http://www.scielo.br/pdf/rbpi/v50n2/a04v50n2 [Acesso em 15 Setembro 2014].

xvIII Observatório de Política Externa do Brasil(2010)Informe de Política Externa Brasileira ${ }^{\circ} 282$. Brasil. Disponível em: http://unesp.br/gedes/produtos/arquivos/m4_u8_12052014-11-19-11.pdf [Acesso em 15 Setembro 2014].

${ }^{\mathrm{XIX}}$ Saraiva, J. F. S. (2002). Política exterior do governo Lula: o desafio africano. Revista Brasileira de Política Internacional [online], 45. Disponível em: http://www.scielo.br/pdf/rbpi/v45n2/a01v45n2.pdf [Acesso em 15 Setembro 2014]. 


\footnotetext{
xx Pautasso, D.; Albanus, A. P. (2012). O Brasil e a Cúpula América do Sul-África: um país emergente nas relações Sul-Sul. Século XXI [online], 3. Disponível em: http://sumarioperiodicos.espm.br/index.php/seculo21/article/viewFile/1837/114 [Acesso em 15 Setembro 2014].

xxI Vizentini, P. G. F.; Pereira, A. D.A política Africana do governo Lula [online]. Disponível em: http://www.ufrgs.br/nerint/folder/artigos/artigo40.pdf [Acesso em 18 Setembro 2014].
}

\section{Referências Bibliográficas}

Brasil. Balanço de Política Externa 2003/2010. [livro eletrônico] Brasília. Disponível em: https://i3gov.planejamento.gov.br/textos/livro6/6.1_Politica_Externa.pdf [Acesso em 15 Setembro 2014].

Brasil. (2008). Discursos selecionados do Presidente Luiz Inácio Lula da Silva. [livro eletrônico] Brasília: Fundação Alexandre de Gusmão. Disponível em:

http://funag.gov.br/loja/download/505-discursos_selecionados_lula.pdf [Acesso em 15 Setembro 2014].

Castro, F. M. O. (2009), Dois séculos de história da organização do Itamaraty, volume I (1808-1979). [livro eletrônico] Brasília: Fundação Alexandre do Gusmão. Disponível em:

http://www.funag.gov.br/biblioteca/dmdocuments/Historia_da_org_do_itamaraty_vol_1 .pdf [Acesso em 15 Setembro 2014].

Castro, F. M. O. (2009), Dois séculos de história da organização do Itamaraty, volume II (1979-2008). [livro eletrônico] Brasília: Fundação Alexandre do Gusmão. Disponível em: http://funag.gov.br/loja/download/561-1808-2008_

_Itamaraty_Dois_Seculos_de_Historia_Vol._2.pdf [Acesso em 15 Setembro 2014].

Cervo, A.; Bueno, C.(2002). História da política exterior do Brasil, Brasília, Editora UnB.

Leite, P. S. (2011).O Brasil e a cooperação Sul-Sul em três momentos [livro eletrônico] Brasília: Fundação Alexandre de Gusmão. Disponível em:

http://www.funag.gov.br/biblioteca/dmdocuments/Cooperacao_sul_sul.pdf[Acesso em 15 Setembro 2014].

Lessa, A. C. (1998). A diplomacia universalista do Brasil: a construção do sistema contemporâneo de relações bilaterais. Revista Brasileira de Política Internacional [online]. Disponível em: http://www.scielo.br/pdf/rbpi/v41nspe/a03v41nspe.pdf [Acesso em 15 Setembro 2014].

Lima, M. R. S. (2005). A política externa brasileira e os desafios da cooperação Sul-Sul. Revista Brasileira de Política Internacional. Disponível em:

http://www.scielo.br/pdf/rbpi/v4

8n1/v48n1a02.pdf [Acesso em 15 Setembro 2014]. 
Mendonça, F. A. P.; Miyamoto, S. (2011). A política externa do governo Geisel (19741979). Século XXI [online], 2. Disponível em: http://sumarioperiodicos.espm.br/index.php/seculo21/article/viewFile/1822/100[Acesso em 15 Setembro 2014].

Muniz, C. B. A. (2009). Discursos selecionados do Presidente Jânio Quadros. [livro eletrônico] Brasília: Fundação Alexandre de Gusmão. Disponível em: http://www.funag.gov.br/biblioteca/dmdocuments/Discursos_janio_quadros.pdf [Acesso em 15 Setembro 2014].

Pautasso, D.; Albanus, A. P. (2012). O Brasil e a Cúpula América do Sul-África: um país emergente nas relações Sul-Sul. Século XXI [online], 3. Disponível em: http://sumario-periodicos.espm.br/index.php/seculo21/article/viewFile/1837/114 [Acesso em 15 Setembro 2014].

Pecequilo, C. S. A Política Externa do Brasil no século XXI: os eixos combinados de cooperação horizontal e vertical. Revista Brasileira de Política Internacional [online]. Disponível em: http://www.scielo.br/pdf/rbpi/v51n2/v51n2a09.pdf [Acesso em 15 Setembro 2014].

Pimentel, J. V. (2000). Relações entre o Brasil e a África subsaárica. Revista Brasileira de Política Internacional [online]. Disponível em: http://www.scielo.br/pdf/rbpi/v43n1/v43n1a01.pdf [Acesso em 15 Setembro 2014].

Rosi, B. G. (2010). As relações Brasil-África no regime militar e na atualidade. Revista Conjuntura Austral [online]. Disponível em: http://seer.ufrgs.br/index.php/ConjunturaAustral/article/view/17764/10935 [Acesso em 15 Setembro 2014].

Saraiva, J. F. (1996). O lugar da África: a dimensão atlântica da política exterior brasileira (de 1946 a nossos dias), Brasília, Editora UnB.

Saraiva, J. F. S. (2002). Política exterior do governo Lula: o desafio africano. Revista Brasileira de Política Internacional [online], 45. Disponível em: http://www.scielo.br/pdf/rbpi/v45n2/a01v45n2.pdf [Acesso em 15 Setembro 2014].

Saraiva, M. G. (2007). As estratégias de cooperação Sul-Sul nos marcos da política externa brasileira de 1993 a 2007. Revista Brasileira de Política Internacional [online], 50. Disponível em: http://www.scielo.br/pdf/rbpi/v50n2/a04v50n2 [Acesso em 15 Setembro 2014].

Teixeira, R. A.; Pinto, E. C. (2012). A economia política dos governos FHC, Lula e Dilma: dominância financeira, bloco no poder e desenvolvimento econômico. Economia e Sociedade [online]. Disponível em:

http://www.scielo.br/pdf/ecos/v21nspe/v21nspea09.pdf [Acesso em 20 Outubro 2014]. 
Vigevani, Tullo; Cepaluni, G. (2007). A política externa de Lula da Silva: a estratégia da autonomia pela diversificação. Contexto Internacional [online], 29. Disponível em: http://www.scielo.br/pdf/cint/v29n2/v29n2a02.pdf[Acesso em 15 Setembro 2014].

Vizentini, P. G. F.; Pereira, A. D.A política Africana do governo Lula [online]. Disponível em: http://www.ufrgs.br/nerint/folder/artigos/artigo40.pdf [Acesso em 18 Setembro 2014].

Vizentini, P. G. F. (2010). South-South cooperation, prestigie diplomacy or "soft imperialism”? Lula's government Brazil-Africa relations. Século XXI [online]. Disponível em: http://sumarioperiodicos.espm.br/index.php/seculo21/article/view/1706/31 [Acesso em 15 Setembro 2014].

Vizentini, P. G. F. (2012). Relações internacionais do Brasil: de Vargas a Lula, São Paulo, Editora Fundação Perseu Abramo. 